\title{
Fitossociologia de campos rupestres quartzíticos e ferruginosos no Quadrilátero Ferrífero, Minas Gerais
}

\author{
Maria Cristina Teixeira Braga Messias ${ }^{1,4}$, Mariangela Garcia Praça Leite ${ }^{2}$, \\ João Augusto Alves Meira-Neto ${ }^{3}$ e Alessandra Rodrigues Kozovits ${ }^{1}$
}

Recebido em 9/03/2011. Aceito em 9/02/2012

\begin{abstract}
RESUMO
(Fitossociologia de campos rupestres quartzíticos e ferruginosos no Quadrilátero Ferrífero, Minas Gerais). Foram realizados estudos fitossociológicos de duas áreas em campos rupestres quartzíticos e ferruginosos (sobre itabirito) de MG. Objetivou-se verificar se os litotipos e as geoformas influenciam a vegetação dessas comunidades. Os campos rupestres de ambas litologias foram estratificados pelas geoformas e fitofisionomias em: 1. Áreas inclinadas, com campos limpos 2. Platôs, com campos limpos e 3. Porções inferiores dos perfis, com campos sujos. Amostraram-se 60 parcelas $(10 \mathrm{x} 10 \mathrm{~m}), 10 \mathrm{em}$ cada habitat. Estimou-se a cobertura e calculou-se a frequência, dominância e valor de importância (VI) das espécies. Calculou-se a diversidade pelo índice de Shannon-Wiener (H') e equabilidade de Pielou (J') para cada habitat e a similaridade florística entre eles pelo índice de Jaccard e análise de agrupamentos. Inventariou-se 165 espécies nos campos quartzíticos e 160 nos ferruginosos. Nos campos rupestres declivosos e nos platôs ferruginosos Vellozia compacta foi a espécie de maior VI. Nos campos inclinados com afloramentos quartzíticos Lagenocarpus rigidus foi a espécie com maior VI, seguida por algumas fanerófitas. Echinolaena inflexa foi a espécie de maior importância nos platôs sobre quartzito, seguida por algumas fanerófitas e várias hemicriptófitas. Os campos sujos sobre itabirito foram dominados por E. erythropappus e V. compacta enquanto que os campos sujos sobre quartzito por Echinolaena inflexa, Eremanthus erythropappus e outras fanerófitas. Os campos sujos foram mais diversos que os campos limpos. Os campos rupestres ferruginosos apresentaram menor diversidade $\left(H^{\prime}=2,92\right)$ e equabilidade $\left(J^{\prime}=0,58\right)$ do que os quartzíticos $\left(H^{\prime}=3,36 ; J^{\prime}=0,66\right)$. A análise de agrupamentos indicou a formação de grupos definidos pelas diferentes litologias e geomorfologias. Os resultados evidenciaram que a geologia e as geoformas influenciam a composição florística de campos rupestres.
\end{abstract}

Palavras-chave: Cadeia do Espinhaço, campos ferruginosos, campos quartzíticos, canga, Quadrilátero Ferrífero

\begin{abstract}
(Phytosociology of quartzitic and ferruginous rocky outcrop areas in the Quadrilátero Ferrífero, Minas Gerais). The floristic composition and phytosociological structure of two areas with quartzitic and ferruginous (itabiritic) campos rupestres in the Quadrilátero Ferrífero region of Minas Gerais state were studied. The aim of this research was to determine if geology and geomorphology influence the vegetation of these communities. The campos rupestres in both lithologies were stratified in three kinds of geomorphologic/phytophysionomic habitats: 1 . Slopes with grasslands; 2 . Plateaus with grasslands and 3. Lower slopes with woody savannas. In each habitat, 10 plots (10x10m) were randomly defined, totaling 60 plots. Frequency, dominance and importance value (IV) parameters were calculated for each species. Shannon-Wiener ( $\left.\mathrm{H}^{\prime}\right)$ and Pielou (J') indexes were estimated for each habitat. Jaccard index and clustering analysis were used to assess the floristic similarity of the different habitats. There were 165 species in the quartzitic and 160 in the ferruginous grasslands. Vellozia compacta was the species with the highest IV in both ferruginous grasslands. Lagenocarpus rigidus was the species with the highest IV in quartzitic sloped areas, followed by several phanerophytes. Echinolaena inflexa was the species with the highest IV in quartzitic plateaus followed by several phanerophytes and many hemicryptophytic species. The woody savannas in ferruginous areas were dominated by $E$. erythropappus and V. compacta, while in quartzitic areas by Echinolaena inflexa, Eremanthus erythropappus and many phanerophytic species. Woody savannas were more diverse than grasslands. Ferruginous campos rupestres exhibited lower diversity $\left(H^{\prime}=2.92\right)$ and equitability $\left(J^{\prime}=0.58\right)$ than quartzitic ones $\left(H^{\prime}=3.36 ; J^{\prime}=0.66\right)$. Cluster analysis produced groups corresponding to the lithological and geomorphological habitats. The results give evidence that geology and geomorphology influence the floristic composition of campos rupestres.
\end{abstract}

Key words: Espinhaço Mountain Range, ferruginous rocky outcrops, laterite, Quadrilátero Ferrífero quartzitic rocky outcrops

\footnotetext{
1 Universidade Federal de Ouro Preto, Departamento de Biodiversidade, Evolução e Meio Ambiente, Ouro Preto, MG, Brasil

Universidade Federal de Ouro Preto, Departamento de Geologia, Ouro Preto, MG, Brasil

Universidade Federal de Viçosa, Departamento de Biologia Vegetal, Viçosa, MG, Brasil

4 Autor para correspondência: cristina@iceb.ufop.br
} 


\section{Introdução}

Os campos rupestres são formações herbáceo-arbustivas em áreas com afloramentos rochosos ou solos rasos, normalmente acima de $900 \mathrm{~m}$, ocorrentes ao longo da Cadeia do Espinhaço e em algumas disjunções (Eiten 1983), no próprio Estado de Minas Gerais, assim como em Goiás e Mato Grosso (Menezes \& Giulietti 1986). Apesar de serem reconhecidos como uma unidade florística, os campos rupestres apresentam notável heterogeneidade de habitats, determinados por fatores edafoclimáticos como: natureza do substrato, topografia, profundidade do solo e microclima (Conceição \& Giulietti 2002; Conceição \& Pirani 2007; Giulietti et al. 1997; Giulietti \& Pirani 1988; Jacobi et al. 2007). Estes autores também relatam diferenças na estrutura da vegetação de campos rupestres dependentemente de aspectos geomorfológicos. Segundo Conceição \& Pirani (2005), nos topos com afloramentos rochosos de quartzito predominam espécies camefíticas de Velloziaceae tolerantes a dessecação, enquanto que em áreas com solos contínuos, correspondentes aos platôs, dominam as hemicriptófitas. Este mesmo padrão também foi observado por Messias et al. (2011) e Lemes (2009). Estudos em inselbergs, que são ecossistemas rochosos montanos, normalmente constituídos de granito-gnaisse, também tem demonstrado uma alta heterogeneidade de habitats relacionados às características da flora, com alta ocorrência de espécies xerofíticas nos afloramentos (Porembski 2007).

No Quadrilátero Ferrífero (QF), em Minas Gerais, são comuns as formações de campos rupestres ferruginosos sobre itabirito (formações ferríferas bandadas) entremeados aos campos rupestres quartzíticos. Nessa região, estes dois tipos litológicos ocorrem nas porções mais altas das montanhas, normalmente acima de $1000 \mathrm{~m}$, uma vez que são as rochas presentes mais resistentes aos processos erosivos (Varajão 1991). Alguns autores, entretanto, colocam os campos quartzíticos e ferruginosos em unidades florísticas distintas (Rizzini 1997) embora muito pouco se conheça da similaridade florística entre os campos sobre estas litologias. Vincent (2004) comparou alguns fragmentos de campos rupestres quartzíticos e ferruginosos na porção oeste do Quadrilátero Ferrífero, porém restritos a alguns tipos de habitat. Mourão \& Stehmann (2007) compararam um campo ferruginoso a nordeste do Quadrilátero Ferrífero com alguns campos quartzíticos e ferruginosos do próprio Quadrilátero, Cadeia do Espinhaço e da Serra de Carajás. Esses autores encontraram baixa similaridade tanto entre as áreas com a mesma litologia, assim como em litologias distintas. Pouco também se sabe sobre a similaridade florística entre campos rupestres, ainda que sobre o mesmo litotipo. Os trabalhos existentes relatam baixa similaridade entre as áreas, justificada principalmente pela presença de barreiras geográficas existentes entre os topos das montanhas aonde estas áreas se localizam, assim como pelo clima, pela matriz vegetacional circundante (Alves \& Kolbek 2009; Jacobi et al.2007; Mourão \& Stehmann 2007), litologia (Vincent 2004) e geoformas (Conceição \& Pirani 2005; 2007), dentre outros fatores. Devido a este fato, os campos rupestres são referidos como possuindo alta diversidade beta (Jacobi et al. 2007), aonde estudos de áreas distintas fornecem informações importantes para compreensão dos padrões de diversidade (Whittaker et al. 2001).

Existem, atualmente, no QF cerca de 50 minas em atividade, responsáveis por aproximadamente $70 \%$ da produção nacional de minério de ferro (DNPM 2010). A mineração é uma das atividades de maior impacto ao ambiente, provocando alterações físicas e químicas drásticas no substrato e, consequentemente, à biota (Griffith \& Toy 2001; Jacobi \& Carmo 2008). Apesar da alta biodiversidade e de estarem sujeitos a alto impacto ambiental, comparativamente, os campos rupestres do QF ainda são pouco estudados e protegidos (Jacobi et al. 2007). De acordo com Lima et al. (2006) uma das causas do insucesso de programas de reabilitação de áreas degradadas por mineração é justamente a falta de conhecimento desses ecossistemas.

Muito embora nos anos recentes tenham sido publicados vários trabalhos sobre a flora de campos rupestres, pouco ainda são os estudos quantitativos (Conceição \& Pirani 2007). Para compreensão dos serviços ecológicos dessas comunidades, assim como para proposição de projetos adequados de recuperação de áreas degradadas, a fitossociologia destaca-se como ferramenta indispensável, inferindo sobre quais as espécies estão presentes, em que proporção, como se distribuem e se associam. Considerando-se a necessidade de incrementar o conhecimento de dados quantitativos a respeito da estrutura fitossociológica dos campos rupestres, este trabalho teve como objetivo caracterizar e comparar a composição florística e a estrutura horizontal de campos rupestres sobre quartzito e itabirito do Quadrilátero Ferrífero, em diferentes habitats, verificando se a geologia e geomorfologia influenciam na distinção de comunidades vegetais em campos rupestres, numa escala local.

\section{Material e métodos}

\section{Área de estudo}

Os campos sobre itabirito e sobre quartzito localizam-se, respectivamente, nos municípios de Ouro Preto $\left(20^{\circ} 10^{\prime} \mathrm{S}\right.$ e $43^{\circ} 31^{\prime} \mathrm{W}$ ) e Mariana ( $20^{\circ} 13^{\prime} \mathrm{S}$ e $\left.43^{\circ} 24^{\prime} \mathrm{W}\right)$, no Quadrilátero Ferrífero, Estado de Minas Gerais. Os dois locais distam entre si de aproximadamente $12 \mathrm{~km}$ em linha reta. A altitude variou de 900 a 1250m. Estas áreas fazem parte da Serra de Ouro Preto e pertencem a Samarco Mineração S.A. e sem registros de queimadas, coleta predatória e pastejo nos últimos 40 anos. As rochas ferruginosas pertencem à Formação Cauê, do grupo Itabira, Supergrupo Minas, enquanto que os quartzitos pertencem ao Grupo Maquiné, do Supergrupo Rio das Velhas (Dorr 1969) (Fig. 1). O clima, de acordo com a classificação de Köppen é Cwb, i.e. mesotérmico, 


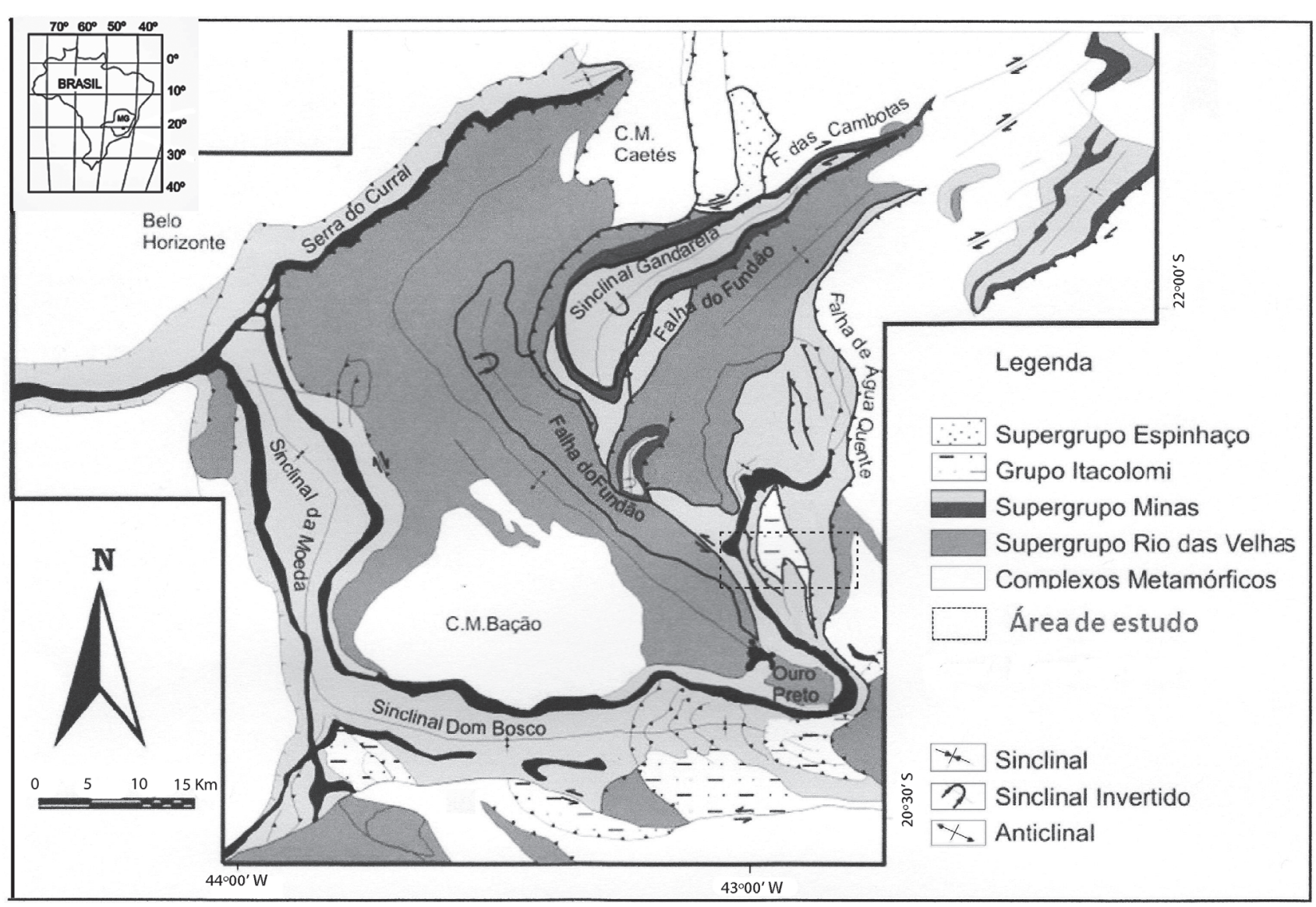

Figura 1. Mapa geológico simplificado do Quadrilátero Ferrífero (Dorr 1969) modificado por Alkmin \& Marshak (1998), indicando a área de estudo.

com a estação chuvosa de novembro a março e invernos secos (Nimer 1989). A precipitação média anual é de 1250 mm e a temperatura média é de $20^{\circ} \mathrm{C}$. Os solos dos campos estudados foram classificados como Neossolos litólicos (EMBRAPA 1999) e exibem diferenças físicas e químicas nas diferentes geoformas e litotipos (Messias 2011).

Os campos rupestres, em ambas as litologias foram estratificados pelas geoformas em: 1 . Áreas inclinadas com afloramentos rochosos, nos topos das elevações, com campos limpos; 2. Platôs, na porção mediana das encostas, com inclinação não ultrapassando a 10\%, com campos limpos e 3. Vales ou depressões localizadas nas porções mais baixas ou côncavas dos perfis, com campos sujos. Ou seja, seis habitats foram estudados, determinados pelas diferenças de litotipo e de geomorfologia (Tab. 1). Em cada litologia, foram estabelecidas aleatoriamente 30 parcelas $(10 \times 10 \mathrm{~m})$, sendo 10 em cada habitat. Os campos limpos em áreas inclinadas, com afloramentos rochosos de itabirito (IAF), possuem grande proporção de rochas aflorantes, exibindo o bandamento típico do itabirito. O solo é muito raso e pedregoso. O substrato dos campos limpos, nos platôs sobre itabirito (IPL) é constituído por afloramentos de concreções ferruginosas, oriundas da laterização do itabirito, conhecidas como cangas couraçadas. Os campos sujos sobre itabirito (ICS) também apresentam cangas, parcialmente cobertas por solo coluvial. Os campos limpos inclinados com afloramentos rochosos de quartzito (QAF) exibem uma grande proporção de rochas aflorantes, com o solo raso, ocupando espaços entre os blocos de rochas ou formando pequenas ilhas de solo nas depressões. Os campos limpos sobre os platôs nas áreas sobre quartzito (QPL) exibem solo arenoso e raso, não ultrapassando $40 \mathrm{~cm}$ de profundidade, continuo e com raros afloramentos rochosos. Os solos nesse habitat mostraram drenagem deficiente durante a estação chuvosa. Os campos sujos sobre quartzito (QCS) apresentam solo arenoso coluvial mais profundo que nos outros habitats, com ocasionais afloramentos rochosos.

\section{Estudos florísticos}

O levantamento florístico e fitossociológico foi realizado de setembro de 2007 a fevereiro de 2009, em excursões semanais ao campo. Foram inventariadas todas as espécies ocorrentes e estimado visualmente o respectivo percentual de cobertura como uma medida de dominância, pela projeção vertical das partes aéreas de cada espécie em relação à área da parcela (Mueller-Dombois \& Ellenberg 1974; Westhoff \& Maarel 1978). A estimação visual das áreas de cobertura das espécies foi realizada similarmente ao método de Braun-Blanquet (Mueller-Dombois \& Ellenberg 1974). No entanto, os valores estimados foram tomados como 
Tabela 1. Habitats de campos rupestres estudados em diferentes litologias e geoformas.

\begin{tabular}{lccc}
\hline Litologia & Geoforma & Fisionomia & Sigla \\
\hline \multirow{2}{*}{ Itabirito } & Áreas inclinadas com afloramentos rochosos, nos topos das elevações & Campos limpos & IAF \\
& Platôs na porção mediana das encostas, com inclinação $\leq 10 \%$ & Campos limpos & IPL \\
& Vales ou depressões localizadas nas porções mais baixas ou côncavas dos perfis & Campos sujos & ICS \\
\hline \multirow{2}{*}{ Quartzito } & Áreas inclinadas com afloramentos rochosos, nos topos das elevações & Campos limpos & QAF \\
& Platôs na porção mediana das encostas, com inclinação $\leq 10 \%$ & Campos limpos & QPL \\
& Vales ou depressões localizadas nas porções mais baixas ou côncavas dos perfis & Campos sujos & QCS \\
\hline
\end{tabular}

variável contínua, ao invés serem categorizados pela escala de cobertura e abundância de Braun-Blanquet. As espécies foram classificadas quanto as suas formas de vida de acordo com Raunkiaer (1934). Todas as espécies foram coletadas, herborizadas, identificadas, classificadas de acordo com o APG (2009) e depositadas no Herbário Professor Jose Badini (OUPR), da Universidade Federal de Ouro Preto. A lista das espécies e suas respectivas formas de vida e coberturas nos diferentes habitats encontra-se em Messias et al. (2011).

Foram calculadas a freqüência absoluta (FA), frequência relativa (FR), dominância absoluta (DoA), dominância relativa (DoR) e valor de importância (VI) para cada espécie, onde os parâmetros de dominância foram calculados a partir dos valores de cobertura. Foram ainda calculados, para cada habitat, a diversidade de espécies pelo índice de Shannon-Wiener (H') e equabilidade de Pielou (J') (Magurran 2004).

Para interpretar a similaridade florística entre as parcelas utilizou-se a análise de agrupamentos de médias não ponderadas (UPGMA), usando-se o índice de similaridade de Jaccard (ISj) como medida de distância (Jongman et al. 1995). A partir dessa análise, foi elaborado um dendrograma, observando-se as hierarquias entre os grupos formados. Para essa análise foi utilizado o programa PAST (Hammer et al. 2001). A análise de adequação dos agrupamentos foi feita pela estimativa do coeficiente de correlação cofenético (Valentin 2000).

\section{Resultados}

Dentre as 64 famílias identificadas, Poaceae (28), Asteraceae (26) e Melastomataceae (19) foram aquelas com o maior número de espécies (Fig. 2). Nos campos rupestres ferruginosos foram encontradas 160 espécies (87 em IAF, 104 em IPL e 128 em ICS) e 165 nos campos rupestres sobre quartzito (85 em QAF, $101 \mathrm{em}$ QPL e $130 \mathrm{em}$ QCS), totalizando 263 espécies (Tab. 2). Analisando o conjunto dos campos rupestres estudados, as famílias com maior VI foram Asteraceae, Poaceae, Velloziaceae, Melastomataceae, Cyperaceae, Myrtaceae, Fabaceae, Orchidaceae, Verbenaceae e Malpighiaceae. As espécies com o maior VI foram Vellozia compacta, Lagenocarpus rigidus, Eremanthus erythropappus, Echinolaena inflexa, Eremanthus crotonoides, Apochloa poliophylla, Clidemia urceolata, Tibouchina heteromalla, Lychnophora pinaster, Eremanthus incanus, Coccoloba acrostichoides, Axonopus laxiflorus, Baccharis reticularia, Periandra mediterranea, Stachytarpheta glabra, Leandra australis, Tapirira guianensis, Schizachyrium tenerum e Byrsonima variabilis e (Tab. 3 e 4).

Nos campos rupestres sobre itabirito, as espécies com maior valor de importância foram, em ordem decrescente, Vellozia compacta, Lagenocarpus rigidus, Apochloa poliophylla, Lychnophora pinaster, Eremanthus erythropappus, Tibouchina heteromalla, Coccoloba acrostichoides, Baccharis reticularia, Periandra mediterranea e Myrcia pulchra (Tab. 3). Vellozia compacta foi a espécie com maior VI, tanto nos campos com afloramentos de itabirito como nos de canga. Os campos declivosos com afloramentos de itabirito foram dominados por V. compacta e L. rigidus (que representam mais de $35 \%$ do VI), ao passo que nos campos com afloramentos de canga observou-se uma maior equitabilidade, sendo dominados por $V$. compacta e $L$. pinaster e sequencialmente por uma variada flora de espécies fanerofíticas (Coccoloba acrostichoides, Tibouchina heteromalla, Myrcia pulchra e Croton erythroxyloides) e hemicriptofiticas (Apochloa poliophylla, Lagenocarpus rigidus e Axonopus siccus). Nos campos sujos sobre itabirito, a espécie com maior VI foi a candeia (Eremanthus erythropappus), seguida por Vellozia compacta.

As espécies com maiores VI nos habitats sobre quartzito foram, em ordem decrescente, Echinolaena inflexa, Eremanthus crotonoides, Clidemia urceolata, Eremanthus erythropappus, Lagenocarpus rigidus, Axonopus laxiflorus, Tapirira guianensis, Eremanthus incanus, Vellozia compacta e Apochloa poliophylla (Tab. 4). Nos campos rupestres inclinados com afloramentos de quartzito (QAF), as espécies com maior VI foram Lagenocarpus rigidus, Eremanthus crotonoides, E. incanus, Clidemia urceolata e Vellozia compacta. Nos platôs sobre quartzito, a espécie com maior VI foi Echinolaena inflexa, seguida de algumas fanerófitas (Clidemia urceolata, Eremanthus crotonoides, Baccharis platypoda e Tapirira guianensis) e muitas hemicriptófítas pertencentes principalmente a Poaceae, Cyperaceae, Eriocaulaceae e Xyridaceae. Nos campos sujos sobre quartzito, Echinolaena inflexa também foi a espécie de maior VI, seguida por várias fanerófítas (Eremanthus erythropappus, E. crotonoides, Clidemia urceolata, Tapirira guianensis, 


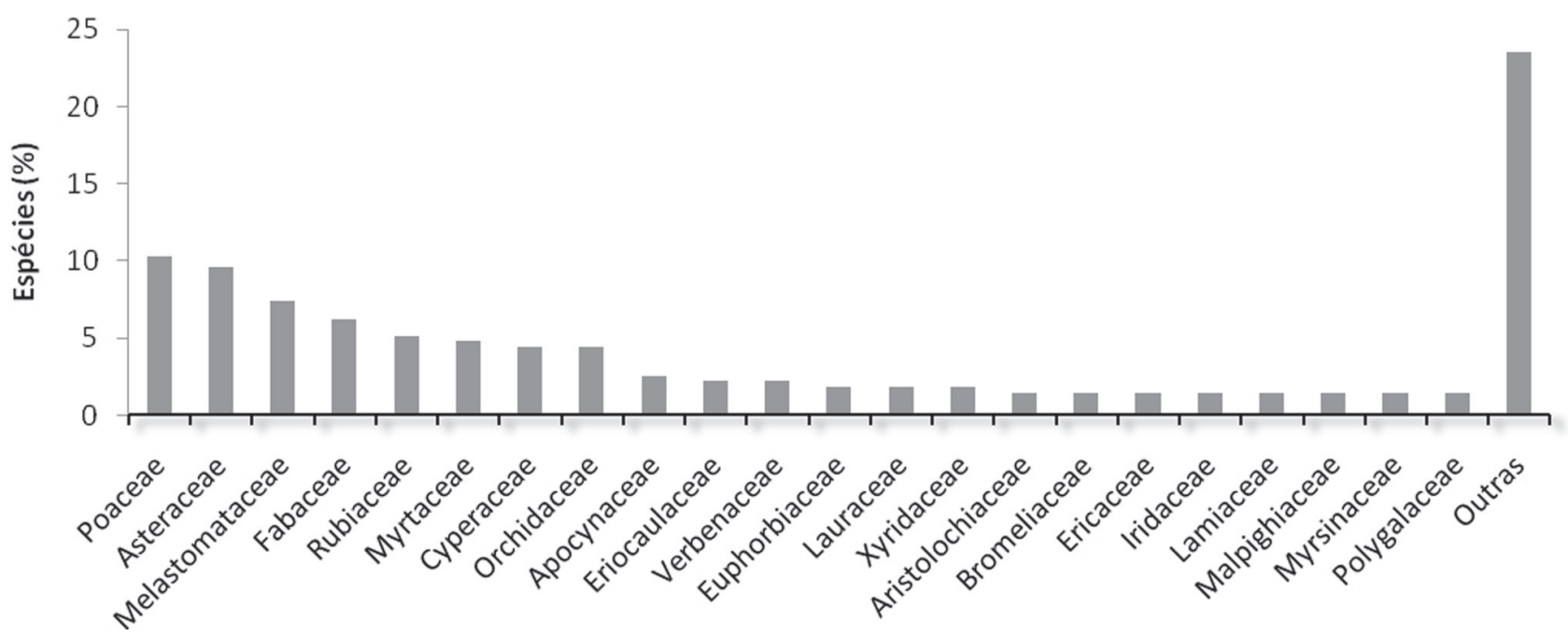

Figura 2. Famílias com maior riqueza (\% espécies) nas duas áreas amostrais de campos rupestres sobre itabirito e quartzito, em Ouro Preto e Mariana, respectivamente.

Tabela 2. Número de espécies (S), Índice de diversidade de Shannon-Wiener $\left(\mathrm{H}^{\prime}\right)$ e Equabilidade de Pielou (J') nos diversos habitats estudados. IAF $=$ Áreas inclinadas, com afloramentos rochosos de itabirito, nos topos das elevações, com campos limpos; IPL = Platôs, com afloramentos de canga couraçada, na porção mediana das encostas, com campos limpos; ICS = Vales ou depressões localizadas nas porções mais baixas ou côncavas dos perfis, com campos sujos; $\mathrm{QAF}=$ Áreas inclinadas com afloramentos rochosos de quartzito, nos topos das elevações, com campos limpos; QPL = Platôs sobre quartzito, na porção mediana das encostas, com campos limpos; QCS = Vales ou depressões nas porções mais baixas ou côncavas dos perfis sobre quartzito, com campos sujos.

\begin{tabular}{lccc}
\hline HABITAT / LITOLOGIA & S & H' & J' \\
\hline IAF & 87 & 2,26 & 0,51 \\
IPL & 104 & 2,71 & 0,58 \\
ICS & 128 & 3,27 & 0,67 \\
QAF & 85 & 2,94 & 0,66 \\
QPL & 101 & 2,83 & 0,61 \\
QCS & 130 & 3,19 & 0,65 \\
QUARTZITO & 165 & 3,36 & 0,66 \\
ITABIRITO & 160 & 2,92 & 0,58 \\
TOTAL & 263 & 3,45 & 0,62 \\
\hline
\end{tabular}

Myrcia amazonica, Pera glabrata, Calea clematidea, Tibouchina heteromalla, Myrcia multiflora e Baccharis reticularia) ainda diversas hemicriptófitas principalmente das famílias Poaceae, Cyperaceae e Orchidaceae.

As espécies mais frequentes foram: Periandra mediterranea, Baccharis reticularia, Tibouchina heteromalla, Apochloa poliophylla, Vellozia compacta, Eremanthus crotonoides, Stachytarpheta glabra e Lagenocarpus rigidus, ocorrendo em mais de $60 \%$ das parcelas (Tab. 3 e 4). No entanto, 64 espécies ocorreram em apenas uma parcela. Muitas espécies foram restritas a determinados tipos de habitat ou ocorreram em apenas uma das litologias (Fig. 3).
Analisando em conjunto todas as comunidades de campos rupestres, o índice de diversidade de Shannon-Wiener, foi $H^{\prime}=3,45$ nats/ind e a equabilidade de Pielou $\left(J^{\prime}\right)=0,62$. O índice de diversidade de Shannon-Wiener nos campos rupestres sobre itabirito foi de 2,92 nats/ind enquanto que nos quartzitos $\mathrm{H}^{\prime}=3,36$ nats/ind (Tab. 2).

Das 263 espécies relatadas, 62 ocorrem nos campos rupestres sobre itabirito e quartzito resultando em $24 \%$ de similaridade florística pelo índice de Jaccard (Fig. 3). Os campos com afloramentos de itabirito foram bastante similares àqueles nos platôs sobre cangas couraçadas (ISj $=0,58$ ). Nos quartzitos, as comunidades mais semelhantes foram os platôs com campos limpos e os campos sujos ( $\mathrm{ISj}=0,52)$. Nos campos ferruginosos os habitats mais dissimilares foram os topos com afloramentos rochosos (IAF) e os campos sujos (ICS) (Fig. 3 e 4 ).

O dendrograma de similaridade (Fig. 4) evidenciou a formação de dois grupos principais constituídos pelas diferentes litologias. Nos campos sobre quartzito, observou-se a consistência do agrupamento das parcelas de acordo com as geoformas, formando primeiramente dois subgrupos: o primeiro com as parcelas dos habitats sobre campos limpos inclinados com afloramentos rochosos (QAF) e um segundo que se subdivide nos campos limpos nos platôs (QPL) e nos campos sujos localizados nos vales ou depressões (QCS). Nos campos sobre itabirito foram observados dois grupos, sendo que o primeiro agrupa principalmente as parcelas dos campos rupestres inclinados com afloramentos de itabirito (IAF) e aquelas dos platôs com canga couraçada (IPL). O segundo grupo é formado principalmente pelas parcelas dos campos sujos (ICS), nos vales e depressões. Todas as comunidades se agruparam com baixa similaridade pelo Índice de Jaccard, sendo QPL a menos dissimilar (Fig. 4). O coeficiente de correlação cofenético $(r=0,88)$ indicou a adequação do dendrograma de similaridade. 
Tabela 3. Parâmetros fitossociológicos das espécies com maior valor de importância $(\Sigma V I=50)$ nos diferentes habitats de campos rupestres sobre itabirito, em Ouro Preto, Minas Gerais. ( $20^{\circ} 10^{\prime} \mathrm{S}$ e $\left.43^{\circ} 31^{\prime} \mathrm{W}\right)$. IAF = Campos rupestres em áreas inclinadas, com afloramentos rochosos de itabirito, nos topos das elevações; IPL = Campos rupestres nos patamares, com afloramentos de canga couraçada, na porção mediana das encostas; ICS = Campos rupestres (campos sujos) sobre canga, em vales ou depressões localizadas nas porções mais baixas ou côncavas dos perfis; $\mathrm{FA}=$ frequência absoluta; $\mathrm{FR}=$ frequência relativa; $\mathrm{DoA}=\mathrm{dominância} \mathrm{absoluta;}$ $\mathrm{DoR}$ = dominância relativa; VI = índice de valor de importância.

\begin{tabular}{|c|c|c|c|c|c|}
\hline \multirow{2}{*}{ Espécies } & FA & FR & DoA & DoR & VI \\
\hline & $\%$ & $\%$ & $\%$ & $\%$ & $\%$ \\
\hline \multicolumn{6}{|l|}{ IAF } \\
\hline Vellozia compacta Mart. ex Schult. \& Schult.f. & 100 & 3,1 & 46,0 & 43,5 & 23,3 \\
\hline Lagenocarpus rigidus Ness & 100 & 3,1 & 22,0 & 20,8 & 12,0 \\
\hline Apochloa poliophylla (Renvoize \& Zuloaga) Zuloaga \& Morrone & 60 & 1,9 & 5,7 & 5,4 & 3,6 \\
\hline Tibouchina heteromalla (D.Don) Cogn. & 100 & 3,1 & 4,3 & 4,0 & 3,6 \\
\hline Baccharis reticularia DC. & 90 & 2,8 & 2,1 & 2,0 & 2,4 \\
\hline Eremanthus incanus (Less.) Less. & 70 & 2,2 & 2,5 & 2,4 & 2,3 \\
\hline Periandra mediterranea (Vell.) Taub. & 90 & 2,8 & 1,5 & 1,4 & 2,1 \\
\hline Diplusodon microphyllus Pohl & 100 & 3,1 & 0,4 & 0,4 & 1,8 \\
\hline \multicolumn{6}{|l|}{ IPL } \\
\hline Vellozia compacta Mart. ex Schult. \& Schult.f. & 100 & 3,0 & 19,0 & 28,6 & 15,8 \\
\hline Lychnophora pinaster Mart. & 80 & 2,4 & 12,3 & 18,5 & 10,5 \\
\hline Apochloa poliophylla (Renvoize \& Zuloaga) Zuloaga \& Morrone & 100 & 3,0 & 5,7 & 8,5 & 5,8 \\
\hline Coccoloba acrostichoides Cham. & 70 & 2,1 & 4,8 & 7,2 & 4,6 \\
\hline Lagenocarpus rigidus Ness & 60 & 1,8 & 4,5 & 6,7 & 4,3 \\
\hline Tibouchina heteromalla (D.Don) Cogn. & 100 & 3,0 & 2,2 & 3,3 & 3,1 \\
\hline Myrcia pulchra (O.Berg) Kiaersk. & 70 & 2,1 & 1,5 & 2,3 & 2,2 \\
\hline Croton erythroxyloides Baill. & 90 & 2,7 & 1,0 & 1,5 & 2,1 \\
\hline Axonopus siccus (Nees) Kuhlm. & 40 & 1,2 & 1,6 & 2,5 & 1,8 \\
\hline \multicolumn{6}{|l|}{ ICS } \\
\hline Eremanthus erythropapus (DC.) MacLeish & 80 & 1,9 & 11,8 & 19,2 & 10,6 \\
\hline Vellozia compacta Mart. ex Schult. \& Schult.f. & 80 & 1,9 & 9,3 & 15,1 & 8,5 \\
\hline Coccoloba acrostichoides Cham. & 90 & 2,2 & 3,2 & 5,2 & 3,7 \\
\hline Apochloa poliophylla (Renvoize \& Zuloaga) Zuloaga \& Morrone & 90 & 2,2 & 3,0 & 4,9 & 3,5 \\
\hline Lagenocarpus rigidus Ness & 70 & 1,7 & 3,2 & 5,1 & 3,4 \\
\hline Trembleya laniflora (D.Don) Cogn. & 50 & 1,2 & 2,7 & 4,4 & 2,8 \\
\hline Eremanthus crotonoides (DC.) Sch.Bip. & 50 & 1,2 & 2,5 & 4,1 & 2,6 \\
\hline Eremanthus incanus (Less.) Less. & 40 & 1,0 & 2,5 & 4,1 & 2,5 \\
\hline Leandra australis (Cham.) Cogn. & 100 & 2,4 & 1,5 & 2,4 & 2,4 \\
\hline Tibouchina heteromalla (D.Don) Cogn. & 90 & 2,2 & 1,6 & 2,6 & 2,4 \\
\hline Myrcia pulchra (O.Berg) Kiaersk. & 70 & 1,7 & 1,9 & 3,0 & 2,3 \\
\hline Byrsonima variabilis A.Juss. & 80 & 1,9 & 1,7 & 2,7 & 2,3 \\
\hline Myrcia venulosa DC. & 50 & 1,2 & 1,6 & 2,5 & 1,9 \\
\hline Periandra mediterranea (Vell.) Taub. & 100 & 2,4 & 0,6 & 1,0 & 1,7 \\
\hline
\end{tabular}

\section{Discussão}

As famílias mais abundantes nos campos rupestres estudados são similares àquelas encontradas em outros levantamentos florísticos de campos rupestres no Quadrilátero Ferrífero (Andrade et al. 1986, Brandão \& Gavilanes 1990, Brandão et al. 1991, Mourão \& Stehmann 2007, Viana \& Lombardi 2007, Lemes 2009), assim como em outras áreas ao longo da Cadeia do Espinhaço (Alves \& Kolbek 2009, Conceição \& Giulietti 2002 e Conceição \& Pirani 2007). Giulietti et al. (1997) descreveram estas famílias como características da Serra do Espinhaço, porém sujeitas a variações em suas riquezas, dependentemente das condições fisiográficas. Jacobi et al. (2007) e Viana \& Lombardi (2007) encontraram maior riqueza de Solanaceae, em campos rupestres ferruginosos localizados a oeste do QF, do que no presente trabalho. Vincent (2004) mencionou também Loranthaceae e Amaranthaceae dentre as famílias como maior riqueza de espécies em campos ferruginosos, também no oeste do QF, diferentemente dos demais estudos.

Algumas das espécies com maior VI nos campos rupestres sobre itabirito foram também citadas como tais na Serra do Rola Moça (Jacobi et al. 2008), como: Lagenocarpus rigidus, Tibouchina heteromalla, Lychnophora pinaster, Stachytarpheta glabra, Hoffmannseggella caulescens e Vellozia compacta. Vincent (2004) também relata Hoffmannseggella caulescens (= Laelia caulescens), Lychnophora pinaster $(=L$. ericoides) e Tibouchina heteromalla ( $=$ T. multiflora) dentre as espécies com maior VI em canga couraçada na Serra do Rola Moça. Jacobi et al. (2007), também relataram Lychno- 
Tabela 4. Parâmetros fitossociológicos das espécies com maior valor de importância $(\Sigma V I=50)$ nos diferentes habitats de campos rupestres sobre quartzito, em Mariana, Minas Gerais. $\left(20^{\circ} 13^{\prime} \mathrm{S}\right.$ e $\left.43^{\circ} 24^{\prime} \mathrm{W}\right)$. QAF = Campos rupestres em áreas inclinadas com afloramentos rochosos de quartzito, nos topos das elevações; $\mathrm{QPL}=$ Campos rupestres nos patamares sobre quartzito, na porção mediana das encostas; QCS = Campos rupestres (campos sujos) sobre quartzito, em vales ou depressões localizadas nas porções mais baixas ou côncavas dos perfis; $F A=$ frequência absoluta; $F R=$ frequência relativa; DoA $=$ dominância absoluta; DoR = dominância relativa; VI = índice de valor de importância.

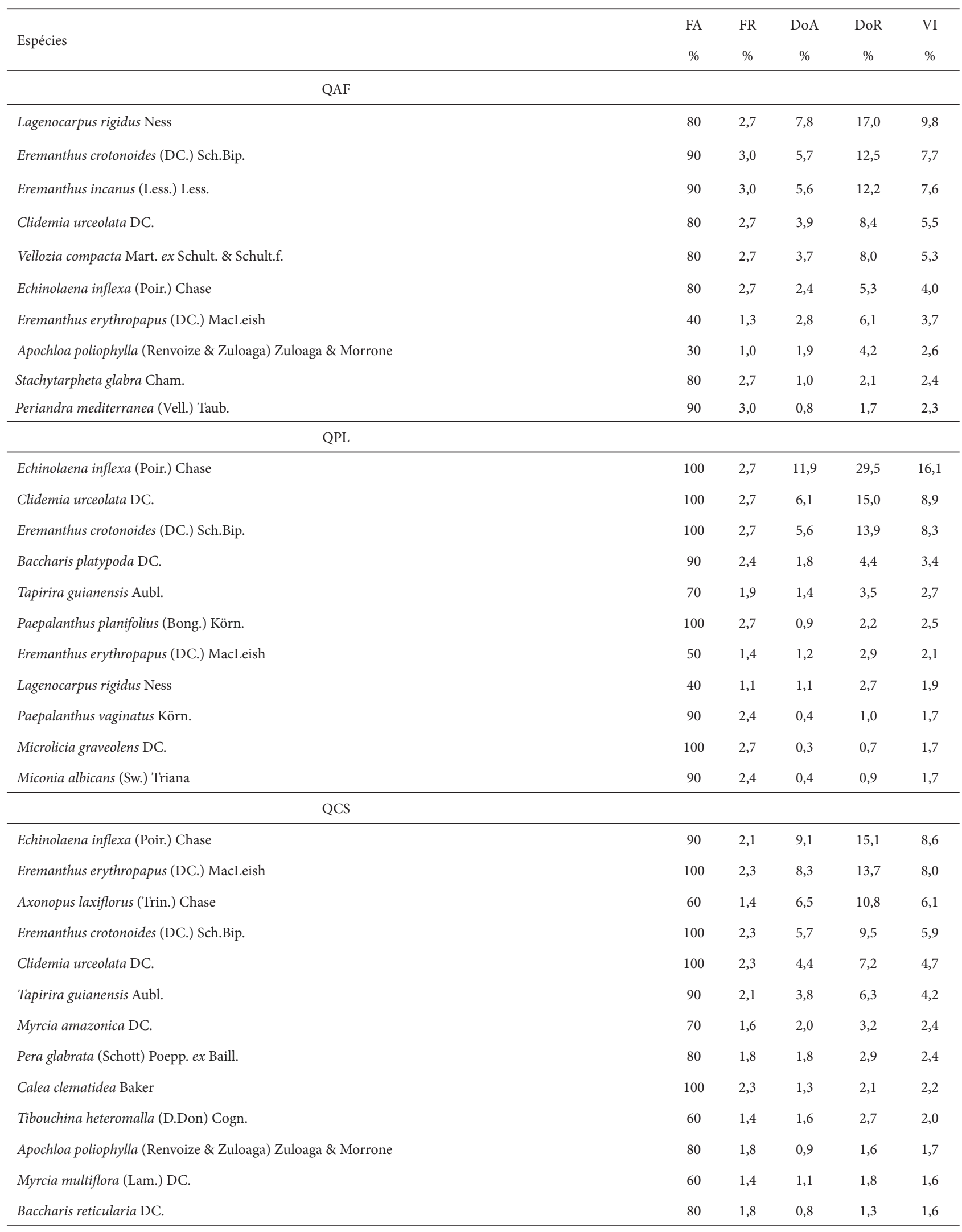



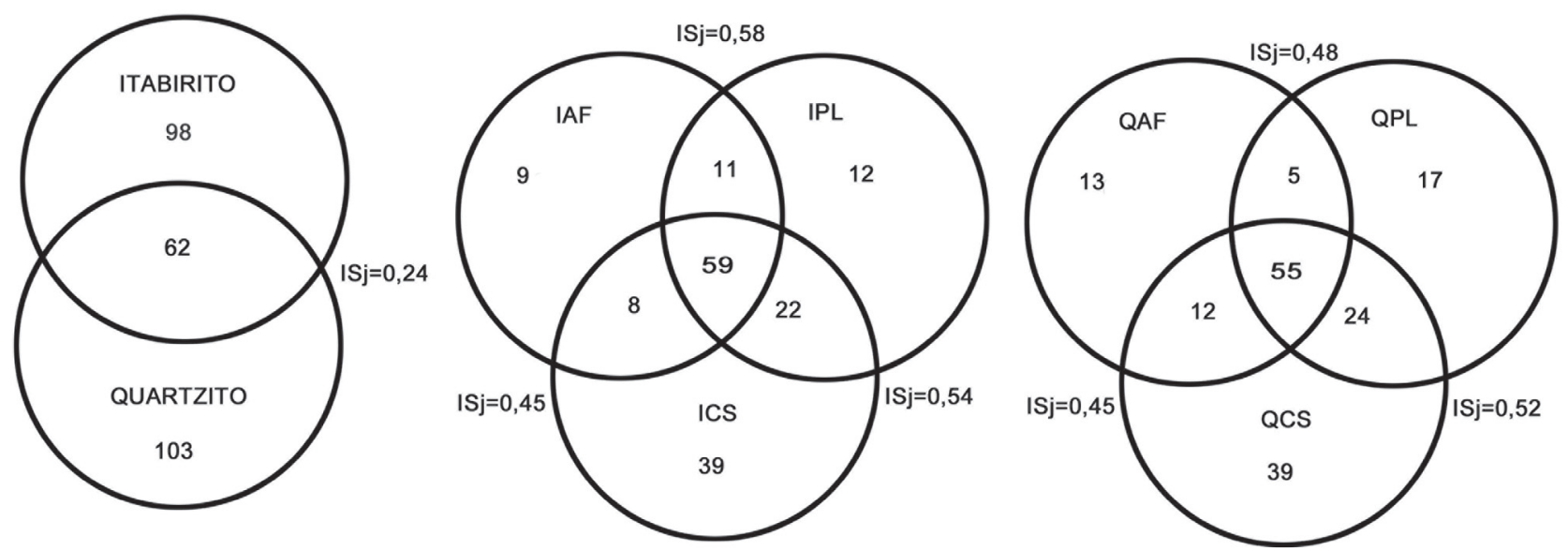

Figura 3. Diagrama de Venn indicando o número de espécies exclusivas e comuns e respectivas similaridades florísticas entre habitats de campos rupestres estudados em Ouro Preto e Mariana MG. ISj = Índice de similaridade de Jaccard; IAF = Áreas inclinadas, com afloramentos rochosos de itabirito, nos topos das elevações, com campos limpos; IPL = Platôs, com afloramentos de itabirito (canga couraçada), na porção mediana das encostas, com campos limpos; ICS = Vales ou depressões localizadas nas porções mais baixas ou côncavas dos perfis sobre itabirito, com campos sujos; QAF = Áreas inclinadas com afloramentos rochosos de quartzito, nos topos das elevações, com campos limpos; QPL = Platôs sobre quartzito, na porção mediana das encostas, com campos limpos; QCS = Vales ou depressões nas porções mais baixas ou côncavas dos perfis sobre quartzito, com campos sujos.

phora pinaster, Baccharis reticularia, Tibouchina heteromalla (= T. multiflora), Lagenocarpus rigidus e Hoffmannseggella caulescens (= Sophronitis caulescens) como mais comuns em campos ferruginosos e Mourão \& Stehmann (2007) também citaram Lychnophora pinaster, Periandra mediterranea e $T$. heteromalla $(=$ T. multiflora) como espécies mais importantes em campos rupestres ferruginosos em Barão de Cocais. Lemes (2009) também relatou T. heteromalla, V. compacta e Baccharis platypoda como espécies com maior VI nos afloramentos rochosos de quartzito no Parque Estadual do Itacolomi, assim como V. compacta, Eremanthus erythropappus, E. incanus e Echinolaena inflexa como de alto VI em áreas semelhantes na Serra de Ouro Branco.

No presente estudo, os habitats com maior proporção de afloramentos rochosos mostraram maior riqueza e abundância de espécies epilíticas vasculares formadoras ou não de "tapetes", descritas por Porembski (2007) para os "inselbergs" tropicais, pertencentes principalmente a Velloziaceae, Bromeliaceae, Cyperaceae e Orchidaceae. Estudos florísticos em campos rupestres têm evidenciado a importância da família Velloziaceae nos afloramentos rochosos (Conceição \& Giulietti 2002; Conceição \& Pirani 2005; 2007). Velloziaceae possui várias espécies tolerantes à dessecação (Aidar et al. 2010; Gaff 1987; Meguro et al. 1977; Meirelles et al. 1997) e como a família com maior número de táxons especialistas em inselbergs (Barthlott \& Porembski 2000). Isto explica a maior importância encontrada para V. compacta nas áreas de campos rupestres sobre itabirito, especialmente em IAF, aonde a proporção de rochas aflorantes é comparativamente maior do que nos quartzitos. Nos campos rupestres sobre quartzito, a dominância de $V$. compacta foi conspícua nos campos inclinados com afloramentos (QAF) pela mesma razão. De acordo com Alves \& Kolbek (2010), solos instáveis e arenosos, como os encontrados nos platôs sobre quartzito, não são propícios ao desenvolvimento de espécies arbustivas perenes de Vellozia.

Dentre os habitats estudados, os platôs sobre quartzito e itabirito foram os que mais divergiram entre si quanto ao tipo de solo (Messias 2011). Nos itabiritos o substrato é mais escasso, constituído por uma grande proporção de couraça laterítica exposta. Nos platôs sobre quartzito observou-se o solo arenoso e raso, porém contínuo, aonde raramente ocorrem afloramentos rochosos. Devido a este fato, as espécies rupícolas e saxícolas praticamente inexistem nos platôs sobre quartzito. Além do mais, durante a época chuvosa, os solos em QPL exibem encharcamento temporário. Nos platôs sobre quartzito, observa-se uma grande heterogeneidade da composição florística entre os diversos levantamentos (Lemes 2009; Conceição \& Giulietti 2002; Conceição et al. 2007; Conceição \& Pirani 2005), no entanto, nota-se a predominância de formas de vida hemicriptofíticas, principalmente das famílias Poaceae, Cyperaceae, Eriocaulaceae e Orchidaceae (Conceição \& Giulietti 2002; Lemes 2009; Messias et al. 2011; Rapini et al. 2008). As hemicriptófitas são quase que exclusivamente Liliopsida, com raízes fasciculadas e explorando a parte mais superficial do solo. Dutra (2005) observou maior umidade na camada mais superficial do solo de campos rupestres quartzíticos, sendo a umidade correlacionada ao teor de matéria orgânica. Desta forma, o domínio desta forma de vida pode ser explicado pelo fato de que no período seco, a porção superficial é mais úmida e rica em nutrientes, devido ao conteúdo de matéria orgânica, ao passo que no período chuvoso, quando ocorre encharcamento temporário dessas áreas, a porção superficial do solo possui melhor aeração. Além disso, várias monocotiledôneas (que são principalmente hemicriptófitas) possuem atributos anatômicos e fisiológicos mais eficientes para adaptação ao encharcamento, 


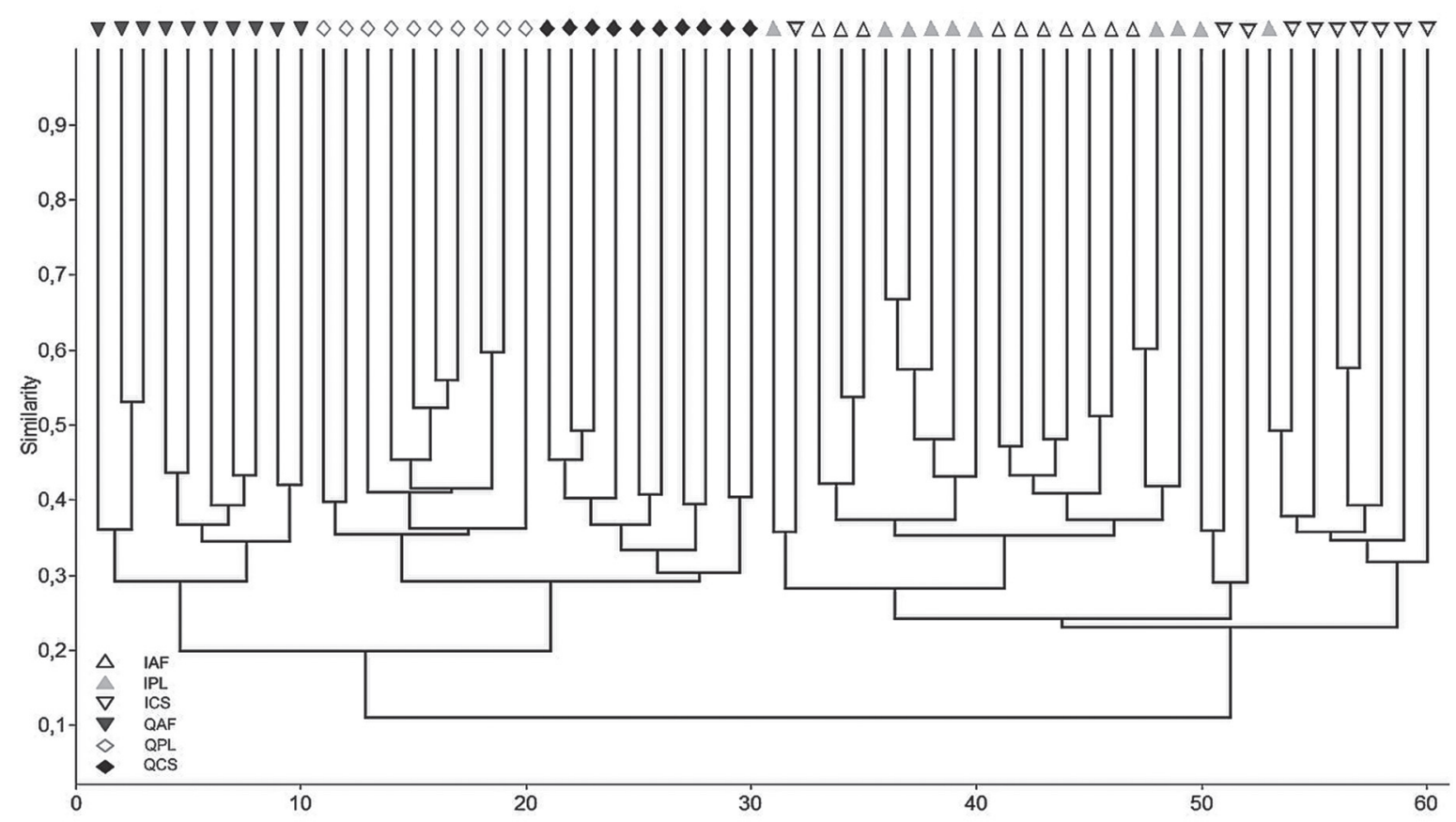

Figura 4. Dendrograma de similaridade entre as parcelas, utilizando análise de agrupamentos por médias não ponderadas (UPGMA) e o índice de Jaccard como distância. IAF = Áreas inclinadas, com afloramentos rochosos de itabirito, nos topos das elevações, com campos limpos; IPL = Platôs, com afloramentos de itabirito (canga couraçada), na porção mediana das encostas, com campos limpos; ICS = Vales ou depressões localizadas nas porções mais baixas ou côncavas dos perfis sobre itabirito, com campos sujos; QAF = Áreas inclinadas com afloramentos rochosos de quartzito, nos topos das elevações, com campos limpos; QPL = Platôs sobre quartzito, na porção mediana das encostas, com campos limpos; QCS = Vales ou depressões nas porções mais baixas ou côncavas dos perfis sobre quartzito, com campos sujos.

justificando a sua dominância em locais alagados (Mollard et al. 2008; Visser et al. 2000).

Muitas espécies fanerofíticas observadas nesse levantamento são também freqüentes em fisionomias florestais, tanto de Cerrado como de Mata Atlântica, como Eremanthus erythropappus, E. incanus, Guatteria vilosissima, Handroanthus albus, Myrcia amazonica, M. splendens, Pera glabrata, Siparuna poeppigii, Tapirira guianensis, Vismia brasiliensis e Xylopia brasiliensis. No entanto, pela limitação da espessura do substrato, normalmente possuem porte menor, não ultrapassando $3 \mathrm{~m}$ de altura. A ocorrência dessas espécies denota a influência da vegetação do entorno na composição dos campos rupestres, como sugerido por Harley (1995) e Viana \& Filgueiras (2008). Estas espécies ocorrem, preferencialmente, nas áreas de campos sujos, localizadas em depressões, ou áreas côncavas nas partes mais baixas dos perfis, aonde o solo coluvial é mais espesso. Também ocorrem nas áreas de campos limpos com afloramentos, em fendas ou entre blocos de rochas, onde se acumula o solo. Nos campos rupestres sobre itabirito, nota-se, mais frequentemente, a ocorrência de fendas verticais nos blocos de rocha ou na crosta laterítica, provavelmente contribuindo para a maior ocorrência de espécies fanerofíticas.

Apesar de restrito a uma pequena área, este estudo colabora com a identificação de endemismos e da distribuição geográfica de espécies dos campos rupestres. Espécies relatadas como endêmicas de campos ferruginosos do Quadrilátero Ferrífero, como Arthrocereus glaziovii (K.Schum.) N.P.Taylor \& Zappi (Taylor \& Zappi 2004) e Mimosa calodendron Mart. ex Benth. (Barneby 1991), não foram coletadas nas áreas de estudo. Vriesea minarum L.B.Sm., foi coletada apenas nos campos ferruginosos das áreas estudadas. Embora esta espécie seja referida como endêmica dos campos ferruginosos (Versieux 2005), há relatos de ocorrência da mesma em campos rupestres quartzíticos nas Serras de Lavras Novas e de Ouro Branco (Guarçoni 2008). Dentre as espécies que ocorreram exclusivamente nas unidades amostrais sobre quartzito, muitas pertencem a Poaceae, Eriocaulaceae e Xyridaceae. Há a necessidade de maiores estudos florísticos nos campos rupestres do QF visando um estudo mais detalhado da sua flora e da distribuição geográfica das espécies.

De acordo com Porembski et al. (1997; 1998), os campos com afloramentos rochosos do Brasil são particularmente diversos, sendo que inselbergs associados à Mata Atlântica brasileira são muito mais diversos do que aqueles encontrados na África. Os autores consideram que esta riqueza seja influenciada pelo Cerrado e Mata Atlântica circundantes. Muito embora os índices de diversidade sejam influenciados pelo desenho e área amostral nos diferentes estudos, os índices de diversidade encontrados nos campos rupestres estudados estão dentro da variação encontrada em levantamentos ao longo da Cadeia do Espinhaço, assim como em "inselbergs" do Rio de Janeiro. Em um afloramento quartzí- 
tico da Chapada Diamantina foram encontrados valores de 2,79 nats/ind (Conceição \& Giulietti 2002); 2,53 nats/ind em campos com afloramento de canga na Serra da Mutuca (Vincent 2004) e valores de 1,74 a 2,96 nats/ind em afloramentos graníticos no Rio de Janeiro (Meirelles et al. 1999). Foi encontrada maior diversidade nos campos ferruginosos do presente estudo do que na Serra do Rola Moça (Jacobi et al. 2008). Os campos rupestres quartzíticos estudados também foram mais diversos do que alguns campos rupestres sobre quartzito-arenito, na Chapada Diamantina, (Conceição \& Giulietti 2002; Conceição et al. 2007). No entanto, valores superiores de diversidade $\left(H^{\prime}=3,52\right)$ foram encontrados por Conceição \& Giulietti (2002) para o Platô 2, também na Chapada Diamantina. Lemes (2009) encontrou valores semelhantes de diversidade nos habitats sobre afloramentos rochosos e platôs sobre quartzito nas Serras do Itacolomi e de Ouro Branco. Este mesmo autor também observou maior diversidade nos campos rupestres com afloramentos do que nos platôs sobre quartzito, como postulado por Conceição \& Pirani (2007). De acordo com estes autores, nas áreas com afloramentos rochosos ocorre maior heterogeneidade ambiental com a formação de diferentes microhabitats, ao passo que os platôs seriam mais homogêneos. No presente estudo, o valor do índice de Shannon-Winer calculado para todos os habitats foi maior do que o calculado isoladamente para cada um deles, demonstrando o aumento da heterogeneidade no conjunto dos ambientes estudados.

Os levantamentos florísticos realizados em campos ferruginosos (Jacobi et al. 2007; Mourão \& Stehmann 2007; Vianna \& Lombardi 2007; Vincent 2004; Vincent \& Meguro 2008) indicam que estes campos possuem menor diversidade do que os quartzíticos (Conceição \& Giulietti 2002; Conceição \& Pirani 2005; 2007; Conceição et al. 2007; Giulietti et al. 1987; Vincent \& Meguro 2008). Nesse estudo, os campos quartzíticos foram também mais diversos que os ferruginosos, quando analisados no conjunto de habitats. Os valores de equitabilidade foram menores nos campos ferruginosos, onde menos espécies apresentam alta dominância, especialmente nos campos limpos com afloramentos de itabirito, aonde Vellozia compacta e Lagenocarpus rigidus representaram mais de 35\% do VI total. Comparativamente, os campos ferruginosos são muito mais restritivos ao estabelecimento de espécies, devido à escassez de substrato e altos teores de metais, além das outras características restritivas comuns aos campos sobre quartzito como: alta exposição a radiação ultravioleta, variação térmica diária, alta evapotranspiração, acidez, baixo teor de nutrientes e reduzida capacidade de retenção de água no solo (Jacobi et al. 2007). Desta forma, poucas espécies mostrando alta adaptação a estas características do ambiente revelaram-se dominantes na comunidade, aonde os menos adaptados não competem eficientemente. No entanto, nesse estudo, foi verificada maior diversidade nos campos sujos sobre itabirito do que nos outros habitats sobre quartzito. A maior diversidade encontrada nos campos sujos (ICS e QCS) parece estar relacionada à disponibilidade de recursos do substrato e à maior extensão das ilhas de vegetação (MacArthur \& Wilson 1967). Devido ao coluvionamento, as manchas de solo são mais extensas e profundas. A menor pressão de seleção nesses habitats permite o estabelecimento de uma comunidade vegetal mais diversa do que nos ambientes muito restritivos, como os afloramentos rochosos (Shure \& Ragsdale 1977; Ware 1990). A menor diversidade e ameaça dos campos ferruginosos é preocupante. A alta biodiversidade de um dado ecossistema tem um papel importante para sua funcionalidade, onde a redundância de espécies que desempenham um mesma função em processos fundamentais garante que se uma delas extinga ou entre em declínio populacional, outras a substituirão, dando continuidade à função ecológica de toda a comunidade. Em ambientes vulneráveis com menor diversidade biológica a perda de uma espécie pode implicar no risco da não substituição adequada de sua funcionalidade (Triantis et al. 2010).

Assim como descrito por Viana \& Filgueiras (2008) e Rizzini (1997), a riqueza de Poaceae foi menor nos campos rupestres sobre itabirito (10 espécies) que nos quartzitos (27 espécies), muito embora algumas espécies que foram exclusivas dos quartzitos já tenham sido relatadas em campos ferruginosos e vice-versa.

Nos quatro levantamentos florísticos sobre campos ferruginosos do Quadrilátero Ferrífero analisados por Jacobi \& Carmo (2008) menos de 5\% das espécies foram comuns a todas as áreas e algumas delas não ocorreram no presente estudo. Comparando os diversos levantamentos florísticos de campos rupestres do QF (Andrade et al. 1986, Brandão \& Gavilanes 1990; Brandão et al. 1991, Brandão \& Silva Filho 1993; Ferreira et al. 1977; Jacobi et al. 2007; Lemes 2009; Magalhães et al. 1986; Mourão \& Stehmann 2007; Peron 1989; Roschel 2000; Viana \& Lombardi 2007; Vincent 2004) e o presente estudo observa-se que eles possuem baixa similaridade florística. Nenhuma espécie ocorreu em todos os levantamentos florísticos de campos rupestres do QF. As espécies Vellozia compacta, Lychnophora pinaster, Byrsonima variabilis e Periandra mediterranea ocorreram em mais de $75 \%$ das localidades. Observa-se também que áreas mais próximas sobre litologias diferentes apresentam maior similaridade florística do que áreas disjuntas com a mesma litologia. A similaridade florística entre os campos rupestres sobre quartzito e itabirito do presente estudo $(\mathrm{ISj}=0,24)$ foi similar àquela encontrada por Jacobi et al. (2007) entre dois campos ferruginosos distantes entre si de $32 \mathrm{~km}(0,27)$. Valores mais elevados de similaridade são encontrados entre locais mais próximos, como os diversos levantamentos realizados na Serra do Rola Moça (Jacobi et al. 2007; Vincent 2004) e serras próximas como Serra da Calçada (Viana \& Lombardi 2007; Vincent 2004), Mutuca (Vincent 2004) e Moeda (Jacobi et al. 2007). O mesmo se observa com relação aos campos quartzíticos, onde se notou maior similaridade entre os levantamentos da Serra de Ouro Branco (Lemes 2009) e Itacolomi (Lemes 2009; Peron 1989) 
do que comparando estes com aqueles da Serra da Calçada (Vincent 2004) ou Morro do Chapéu (Andrade et al. 1986). Comparando os campos ferruginosos do presente estudo com os demais, observou-se maior similaridade com aquele estudado por Mourão \& Stehmann (2007) e Roschel (2000) ( $\mathrm{ISj}=0,16$ e ISj $=0,18$, respectivamente), do que com os outros a oeste do QF. Isto sugere que a distância geográfica também seja um forte determinante da similaridade florística, juntamente com a litologia. No entanto, discrepâncias no esforço amostral podem levar a informações equivocadas nas relações florísticas e de falsas ausências (Gaston 1994), especialmente nos campos rupestres aonde existem muitas espécies pouco freqüentes (Rapini et al. 2008). A baixa similaridade nos campos rupestres indica uma alta diversidade beta, justificada pela ocorrência de barreiras geográficas e pela heterogeneidade do ambiente, condicionada, dentre outros fatores, pela litologia e geomorfologia. Mesmo que os campos rupestres apresentem a mesma litologia, as rochas, e consequentemente os solos dela derivados, apresentam variações químicas e físicas (Benites et al. 2007), que também contribuem para a heterogeneidade ambiental.

O dendrograma de similaridade evidenciou a influência da litologia e geoformas na flora dos campos rupestres. $\mathrm{O}$ campo quartzítico com afloramentos rochosos (QAF) foi o habitat mais dissimilar dentre aqueles dos quartzitos, possuindo 13 espécies exclusivas, dentre as 85 ocorrentes, sendo estas principalmente epilíticas ou saxícolas. QPL foi mais similar a QCS, apresentando 79 espécies em comum. A maior similaridade florística entre estes dois habitats se deve, provavelmente, à existência de solo arenoso continuo e menos afloramentos rochosos. Nos campos sobre itabirito observou-se dois grupos, sendo que o primeiro agrupa principalmente as parcelas dos campos limpos com afloramentos de itabirito (IAF) e de canga (IPL). O segundo grupo é formado principalmente pelas parcelas dos campos sujos (ICS). Os campos limpos com afloramentos de itabirito nos topos das elevações (IAF) e os campos limpos dos platôs sobre cangas couraçadas (IPL) provavelmente não formaram grupos distintos por que foi utilizada a matriz de presença e ausência na análise de grupamentos. Muito embora o itabirito, apresentando as rochas bandadas, seja química e estruturalmente bastante diferente das lateritas (conhecidas como cangas) (Rosière \& Chemale Jr. 2000), estes dois habitats apresentaram uma considerável similaridade florística $(\mathrm{ISj}=0,58)$, porém se diferenciando na proporção das espécies dentro de cada uma dessas comunidades. Os campos inclinados com afloramentos de itabirito parecem ser ainda mais restritivos às espécies vegetais, com alta dominância dos táxons melhor adaptados como Vellozia compacta. A grande semelhança entre estes habitats reside no fato da grande porcentagem de rochas expostas, formando ambientes propícios ao desenvolvimento de espécies epilíticas e saxícolas, assim como nas propriedades físicas do solo (Messias 2011). Já os campos sujos ferruginosos (ICS), encontrados nos vales ou depressões, se discriminam dos demais campos sobre itabirito principalmente pela presença de solo mais desenvolvido, permitindo o desenvolvimento de espécies fanerofíticas de maior porte.

A baixa similaridade entre os levantamentos já realizados sugere a necessidade urgente de estudos complementares abrangendo áreas ainda não estudadas, especialmente aquelas localizadas ao sul e sudoeste do QF. Existem apenas duas unidades de conservação de proteção integral possuindo campos ferruginosos sobre itabirito, sobre o controle do Estado: o Parque Estadual da Serra do Rola Moça e a Estação Ecológica dos Fechos (IEF 2008), sendo estas, contíguas. A grande biodiversidade alfa e beta, alto endemismo e a presença de muitas espécies ameaçadas (Jacobi et al. 2007) apontam a necessidade de identificação de áreas prioritárias e subseqüente criação de um número maior de unidades de conservação contemplando diferentes áreas de campos ferruginosos no QF. E ainda, uma vez que as atividades de mineração são altamente impactantes, os campos rupestres do QF necessitam de estudos ecológicos que subsidiem os planos de recuperação de áreas degradadas, indicando possibilidades de restauração do ambiente com características mais próximas do habitat original. Urge também a necessidade de implantação de um sistema eficiente de planos de recuperação de áreas degradadas de longo prazo.

A similaridade florística encontrada entre campos rupestres quartzíticos e ferruginosos apresenta índices similares aos encontradas entre campos da mesma litologia. Portanto, num contexto fitogeográfico, os campos ferruginosos podem ser considerados como campos rupestres, assim como sugerido originalmente por Semir (1991) e posteriormente modificado, dentre outros, por Vincent \& Meguro (2007), acrescendo-se a denominação da rocha aflorante. No entanto, pela peculiaridade da flora e ocorrência de endemismos, a observância legal da preservação das diversas modalidades de campos rupestres deve ser respeitada de modo a garantir a preservação da biodiversidade.

\section{Agradecimentos}

Os autores agradecem a Jorge Luis da Silva e Auria Cordeiro Tonaco pelo auxílio nos trabalhos de campo. À FAPEMIG pelo auxílio financeiro (CRA APQ 00601-08). À Samarco pelo apoio operacional e permissão de estudo nas áreas experimentais.

\section{Referências}

Aidar, S.T.; Meirelles; S.T.; Pocius, O.; Delitti, W.B.C.; Souza; G.M. \& Gonçalves, A.N. 2010. Desiccation tolerance in Pleurostima purpurea (Velloziaceae). Plant Growth Regulation 62: 193-202.

Alkmim, F.F. \& Marshak, S. 1998. Transamazonian orogeny in the southern São Francisco Craton Region, Minas Gerais, Brazil: evidence for paleoproterozoic collision and collapse in the Quadrilátero Ferrífero. Precambrian Research 90: 29-58.

Alves, R.J.V. \& Kolbek, J. 2009. Summit vascular flora of Serra de São José, Minas Gerais, Brazil. Check List 5: 35-73. 
Alves, R.J.V. \& Kolbek, J. 2010. Vegetation strategy of Vellozia crinita (Velloziaceae). Biologia 65: 254-264.

Andrade, P.M.; Gontijo, T.A. \& Grandi, T.S.M. 1986. Composição florística e aspectos estruturais de uma área de Campo Rupestre do Morro do Chapéu, Nova Lima, Minas Gerais. Revista Brasileira de Botânica 9: 13-21.

APG (Angiosperm Phylogeny Group). 2009. An update of the angiosperm phylogeny group classification for the orders and families of flowering plants: APG III. Botanical Journal of the Linnean Society 161: 105-121.

Barneby, R.C. 1991. Sensitivae censitae: a description of the genus Mimosa Linnaeus (Mimosaceae) in the New World. New York, The New York Botanical Gardens.

Barthlott, W. \& Porembski, S. 2000. Vascular plants on inselbergs: systematic overview. Pp.103-116. In: S. Porembski \& W. Barthlott (Eds.). Inselbergs - biotic diversity of isolated rock outcrops in tropical and temperate regions. Ecological Studies. Berlin, Springer-Verlag.

Benites, V.M.; Schaefer, C.E.G.R.; Simas, F.N.B. \& Santos, H.G. 2007. Soil associated with rock outcrops in the Brazilian mountain ranges Mantiqueira and Espinhaço. Revista Brasileira de Botânica 30: 569-577.

Brandão, M. \& Gavilanes, M.L. 1990. Mais uma contribuição para o conhecimento da Cadeia do Espinhaço em Minas Gerais, Serra da Piedade - II. Daphne 1: 26-43.

Brandão, M. \& Silva Filho, P.V. 1993. Os campos rupestres no município de Barão de Cocais, MG. Daphne 3: 11-20.

Brandão, M.; Gavilanes, M.L.; Laca-Buendia, J.P; Macedo, J.F. \& Cunha, L.H.S. 1991. Contribuição para o conhecimento da Cadeia do Espinhaço em Minas Gerais (Serra de Itabirito) - III. Daphne 1: 39-41.

Conceição, A.A. \& Giulietti, A.M. 2002. Composição florística e aspectos estruturais de campo rupestre em dois platôs no Morro do Pai Inácio, Chapada Diamantina, Bahia, Brasil. Hoehnea 29: 37-48.

Conceição, A.A. \& Pirani, J.R. 2005. Delimitação de habitats em campos rupestres na Chapada Diamantina, Bahia: substratos, composição florística e aspectos estruturais. Boletim de Botânica da Universidade de São Paulo 23: 85-111.

Conceição, A.A.; Pirani, J.R. \& Meirelles, S.T. 2007. Floristics, structure and soil of insular vegetation in four quartzite-sandstone outcrops of "Chapada Diamantina", Northeast Brazil. Revista Brasileira de Botânica 30: 641-656.

Conceição, A.A. \& Pirani, J.R. 2007. Diversidade em quatro áreas de campos rupestres na Chapada Diamantina, Bahia, Brasil: espécies distintas, mas riquezas similares. Rodriguésia 58: 193-206.

DNPM (Departamento Nacional de Produção Mineral). 2010. Sumário mineral 2009. Brasília, DNPN.

Dorr, J.V.N. 1969. Physiographic, stratigraphic and structural development of the Quadrilátero Ferrífero. Professional Paper 641-A. Washington, USGS/DNPM.

Dutra,V.F. 2005. Levantamento de Leguminosae Adans. nos Campos Rupestres do Parque Estadual do Itacolomi, MG: florística, preferência por habitat, aspectos reprodutivos e distribuição geográfica. Dissertação de Mestrado. Viçosa, Universidade Federal de Viçosa.

Eiten, G. 1983. Classificação da vegetação do Brasil. Brasília, CNPq/ Coordenação Editorial.

EMBRAPA. 1999. Sistema brasileiro de classificação de solos. Rio de Janeiro, EMBRAPA.

Ferreira, M.B.; D’Assumpção, W.R.C. \& Magalhães, G.M. 1977. Nova contribuição para o conhecimento da vegetação da Cadeia do Espinhaço ou Serra Geral (Maciço do Caraça). Oréades 10: 49-67.

Gaff, D.F. 1987. Desiccation tolerant plants in South America. Oecologia 74: $133-136$.

Gaston, K.J. 1994. Rarity. London, Chapman \& Hall.

Giulietti, A.M.; Menezes, N.L.; Pirani, J.R.; Meguro, M. \& Wanderley, M.G.L. 1987. Flora da Serra do Cipó, Minas Gerais: Caracterização e Lista das Espécies. Boletim de Botânica da Universidade de São Paulo 9: 1-151.

Giulietti, A.M. \& Pirani, J.R. 1988. Patterns of geographical distribution of some plant species from Espinhaço range, Minas Gerais and Bahia, Brazil. Pp. 39-69. In: Vanzolini, P.E. \& Heyer, W.R. (Eds.). Proceedings of a workshop on Neotropical distribution patterns. Rio de Janeiro, Academia Brasileira de Ciências.
Giulietti, A.M.; Pirani, J.R. \& Harley, R.M. 1997. Espinhaço Range Region, Eastern Brazil. Pp. 397-404. In: Davis, S.D.; Heywood, V.H.; HerreraMacBride, O.; Villa-Lobos, J.\& Hamilton, A.C. (Eds.). Centres of plant diversity. A guide and strategy for their conservation. The Americas. Cambridge, IUCN Publication Unity.

Griffith, J. \& Toy, T.J. 2001. Evolution in revegetation of iron-ore mines in Minas Gerais State, Brazil. Unasylva 52: 9-15.

Guarçoni, E.A.E. 2008. Bromeliaceae Juss. no Parque Estadual da Serra do Rola-Moça, Minas Gerais, Brasil: Florística, distribuição e aspectos reprodutivos de Andrea selloana (Baker) Mez. Dissertação de Mestrado. Viçosa, Universidade Federal de Viçosa.

Hammer, O.; Harper, D.A.T. \& Ryan, P.D. 2001. PAST: Palaeontological Statistics software package for education and data analysis. Version 2.04. Paleontologia electronica 4: $9 \mathrm{http}: / /$ folk.uio.no/ohammer/past (Acesso em 25/10/2010).

Harley, R.M. 1995. Introdução. In: Stannard, B.L. (Ed.). Flora of the Pico das Almas, Chapada Diamantina - Bahia, Brazil. Kew, Royal Botanic Gardens.

IEF 2008. Identificação de áreas prioritárias para implantação de sistemas de áreas protegidas e corredores ecológicos no setor sul da região metropolitana de Belo Horizonte. Série Meio Ambiente. Vol.1. AMDA / Instituto Estadual de Florestas-IEF. http://www.redeapasul. com.br/conheca_a_apa_sul_biodiversidade/corredores.pdf (Acesso em 08/12/2010).

Jacobi, C.M.; Carmo, F.F.; Vincent, R.C. \& Stehmann, J.R. 2007. Plant communities on ironstone outcrops: a diverse and endangered Brazilian ecosystem. Biodiversity and Conservation 16: 2185-2200.

Jacobi, C.M.; Carmo, F.F. \& Vincent, R.C. 2008. Estudo fitossociológico de uma comunidade vegetal sobre canga como subsídio para a reabilitação de áreas mineradas no Quadrilátero Ferrífero, MG. Revista Árvore 32: 345-353.

Jacobi, C.M. \& Carmo, F.F. 2008. Diversidade dos campos rupestres ferruginosos no Quadrilátero Ferrífero, MG. Megadiversidade 4: 24-32.

Jongman, R.H.; Ter Braak, C.J.F. \& van Tongeren, O.F.R. 1995. Data analysis in community and landscape ecology. Cambridge, Cambridge University Press.

Lemes, F.O.A. 2009. Relações florísticas, fitossociológicas e aspectos edáficos de comunidades de campos rupestres da Serra do Itacolomi e Serra de Ouro Branco, Minas Gerais. Dissertação de Mestrado. Ouro Preto, Universidade Federal de Ouro Preto.

Lima, H.M.; Flores, J.C.C. \& Costa, F.L. 2006. Plano de recuperação de áreas degradadas versus plano de fechamento de mina: um estudo comparativo. Revista da Escola de Minas 59: 397-402.

MacArthur, R.H. \& Wilson, E.O. 1967. The theory of island biogeography. Princeton, Princeton University Press.

Magalhães, G.M.; Brandão, M.; Badini, J.; Santos, A.K.O. \& Zurlo, M.A. 1986. Contribuição para conhecimento da vegetação da Cadeia do Espinhaço (Serra Geral) - Maciço do Caraça e adjacências. Pp. 395-425. In: Anais do XXXVII Congresso Nacional de Botânica. Ouro Preto 1986, Ouro Preto, Ouro Preto, SBB/UFOP.

Magurran, A.E. 2004. Measuring biological diversity. Oxford, Blackwell Science.

Meguro, M.; Joly, C.A. \& Bittencourt, M.M. 1977. Stress hídrico e alguns aspectos do comportamento fisiológico em Xerophyta plicata Spreng. - Velloziaceae. Boletim de Botânica da Universidade de São Paulo 5: $27-42$.

Meirelles, S.T.; Mattos, E.A. \& Silva, A.C. 1997. Potential desiccation tolerant vascular plants from Southeastern Brazil. Polish Journal of Environmental Studies 6: 17-21.

Meirelles, S.T.; Pivello, V.R. \& Joly, C.A. 1999. The vegetation of granite rock outcrops in Rio de Janeiro, Brazil, and the need for its protection. Environmental Conservation 26: 10-20.

Menezes, N.L. \& Giulietti, A.M. 1986. Campos Rupestres: Paraíso Botânico da Serra do Cipó. Ciência Hoje 5: 38-44.

Messias, M.C.T.B. 2011. Fatores ambientais condicionantes da diversidade florística em campos rupestres quartzíticos e ferruginosos no Quadrilátero Ferrífero, Minas Gerais. Tese de doutorado. Ouro Preto, Universidade Federal de Ouro Preto. 
Messias, M.C.T.B.; Leite, M.G.P.; Meira-Neto, J.A.A.; Kozovits, A.R. 2011. Life-form spectra of quartzite and itabirite rocky outcrop sites, Minas Gerais, Brazil. Biota Neotropica 11(2): 1-14.

Mollard, F.P.O.; Striker, G.G.; Ploschuk, E.L.; Vega, A.S. \& Insaustia, P. 2008. Flooding tolerance of Paspalum dilatatum (Poaceae: Paniceae) from upland and lowland positions in a natural grassland. Flora 203: 548-556.

Mourão, A. \& Stehmann, J.R. 2007. Levantamento da flora do campo rupestre sobre canga hematítica couraçada remanescente na mina do Brucutu, Barão de Cocais, Minas Gerais, Brasil. Rodriguesia 58: 775-786.

Mueller-Dombois, D. \& Ellenberg, H. 1974. Aims and methods of vegetation ecology. New York, Willey and Sons.

Nimer, E. 1989. Climatologia do Brasil. Rio de Janeiro, IBGE.

Peron, M.V. 1989. Listagem preliminar da flora fanerogâmica dos Campos Rupestres do Parque Estadual do Itacolomi, Ouro Preto/Mariana, MG. Rodriguesia 67: 63-69.

Porembski, S.; Seine, R. \& Barthlott, W. 1997. Inselberg vegetation and the biodiversity of granite outcrops. Journal of the Royal Society of Western Australia 80: 193-199.

Porembski, S.; Martinelli, G.; Ohlemüller, R. \& Barthlott, W. 1998. Diversity and ecology of saxicolous vegetation mats on inselbergs in the Brazilian Atlantic rainforest. Diversity and distributions 4: 107-119.

Porembski, S. 2007. Tropical inselbergs: habitat types, adaptive strategies and diversity patterns. Revista Brasileira de Botânica 30: 579-586.

Rapini, A.; Ribeiro, P.L.; Lambert, S. \& Pirani, J.R. 2008. A flora dos campos rupestres da Cadeia do Espinhaço. Megadiversidade 4: 15-23.

Raunkiaer, C. 1934. The life forms of plants and statistical geography. Oxford, Claredon Press.

Rizzini, C.T. 1997. Tratado de fitogeografia do Brasil: aspectos ecológicos, sociológicos e florísticos. Rio de Janeiro, Âmbito Cultural.

Roschel, M.B. 2000. Levantamento florístico fanerogâmico do campo rupestre da Estrada da Torre, Antônio Pereira, Ouro Preto, MG. Dissertação de Mestrado. Rio de Janeiro, Universidade Federal do Rio de Janeiro.

Rosière, C.A. \& Chemale Jr., F. 2000. Itabiritos e minérios de ferro de alto teor do Quadrilátero Ferrífero - uma visão geral e discussão. Geonomos 8: 27-42.

Semir, J. 1991. Revisão taxonômica de Lychnophora Mart. (Vernoniaeae: Compositae). Tese de doutorado. Campinas, Universidade Estadual de Campinas.

Shure, D.J. \& Ragsdale, L. 1977. Patterns of primary succession on granite outcrop surfaces. Ecology 58: 993-1006.
Taylor, N. \&, Zappi, D. 2004. Cacti of eastern Brazil. Kew, The Royal Botanic Gardens.

Valentin, J.L. 2000. Ecologia Numérica - uma introdução à análise multivariada de dados ecológicos. Rio de Janeiro, Interciência.

Triantis, K.A.; Borges, A.V.; Ladle, R.J.; Hortal, J.; Cardoso, P.; Gaspar, C; Dinis, F.; Mendonça, E.; Silveira, L.M.A.; Gabriel, R.; Melo, C.; Santos, A.M.C.; Amorim, I.R.; Ribeiro, S.P.; Serrano, A.R.M.; Quartau, J.A. \& Whittaker, R.J. 2010. Extinction debt on oceanic islands. Ecography 33: $285-294$.

Varajão, C.A.C. 1991. A questão da correlação das superfícies de erosão do Quadrilátero Ferrífero, Minas Gerais. Revista da Escola de Minas 21: 138-145.

Versieux, L.M. 2005. Bromeliáceas de Minas Gerais: catálogo, distribuição geográfica e conservação. Dissertação de Mestrado. Rio de Janeiro, Universidade Federal do Rio de Janeiro.

Viana, P.L. \& Lombardi, J.A. 2007. Florística e caracterização dos campos rupestres sobre canga na Serra da Calçada, Minas Gerais, Brasil. Rodriguésia 58: 159-177.

Viana, P.L. \& Filgueiras, T.S. 2008. Inventário e distribuição geográfica das gramíneas (Poaceae) na Cadeia do Espinhaço, Brasil. Megadiversidade 4: 99-116.

Vincent, R.C. 2004. Florística, fitossociologia e relações entre a vegetação e o solo em áreas de campos ferruginosos no Quadrilátero Ferrífero, Minas Gerais. Tese de Doutorado. São Paulo, Universidade de São Paulo.

Vincent, R.C. \& Meguro, M.M. 2008. Influence of soil properties on the abundance of plants species in ferruginous rocky soils vegetation, southeastern Brazil. Revista Brasileira de Botânica 3: 377-388.

Visser, E.J.W.; Colmer, T.D.; Blom, C.W.P.M. \& Voesenek, C.J. 2000. Changes in growth, porosity and radical oxygen loss from adventitious roots of selected mono- and dicotyledonous wetland species with contrasting types of aerenchyma. Plant, Cell \& Environment 23: $1237-1245$.

Ware, S. 1990. Adaptation to substrate-and lack of it-in rock outcrop plants: Sedum and Arenaria. American Journal of Botany 77: 1095-1100.

Westhoff, V. \& Maarel, E. 1978. The Braun-Blanquet approach. Pp. 289374. In: Whittaker, R.H. (Ed.). Classification of plant communities. Netherlands, Dr. W. Junk.

Whittaker, R.J.; Willis, K.J. \& Field, R. 2001. Scale and species richness: towards a general hierarchical theory of species diversity. Journal of Biogeography 28: 453-470. 